\title{
Substituição de monensina sódica por bicarbonato de sódio em dietas de novilhas confinadas
}

\author{
[Evaluation of the replacement of Monensin with Sodium Bicarbonate in \\ diets for confined bovines] \\ A.P. Oliveira ${ }^{1}$, R.A. Reis ${ }^{1}$, L.M.A. Bertipaglia ${ }^{2}$, G.M.P. Melo ${ }^{2}$, T.T. Berchielli ${ }^{1}$, \\ J.A. Oliveira ${ }^{1}$, D.R. Casagrande ${ }^{3}$, M.A.A. Balsalobre ${ }^{4}$ \\ ${ }^{1}$ FCAV-Unesp - Jaboticabal, SP \\ ${ }^{2}$ Unicastelo - Descalvado, SP \\ ${ }^{3}$ Universidade Federal de Lavras - Lavras, MG \\ ${ }^{4}$ Bellman Nutrição Animal - Mirassol, SP
}

\begin{abstract}
RESUMO
Avaliaram-se os efeitos da substituição da monensina sódica pelo bicarbonato de sódio em dietas de novilhas em confinamento em relação ao desempenho animal, à conversão alimentar e ao parâmetro de fermentação ruminal. Foram utilizadas 56 novilhas mestiças, confinadas por 112 dias, submetidas a dietas com duas porcentagens de concentrado, $50 \%$ e $80 \%$ da matéria seca, com adição de monensina sódica ou bicarbonato de sódio, em fatorial $2 \times 2$. O volumoso utilizado para compor as dietas testadas foi composto de silagem de milho e cana-de-açúcar na proporção de 60:40, respectivamente. O nitrogênio amoniacal foi maior nos animais alimentos com dietas com alto grão. A monensina, na dieta 80:20, proporcionou maiores valores de nitrogênio amoniacal, uma e nove horas após o consumo da ração. O uso de bicarbonato promoveu os maiores valores de $\mathrm{pH}$ ruminal na dieta com 50\% de concentrado, de seis a 18 horas após o consumo. Não houve efeito do aditivo sobre o desempenho animal. A alta inclusão de grãos na dieta propiciou aumento do desempenho animal e da eficiência alimentar. Conclui-se que o uso de bicarbonato de sódio em dietas para terminação de animais em confinamento é uma opção viável em substituição à monensina sódica para a manipulação da fermentação ruminal.
\end{abstract}

Palavras-chave: bovinos de corte, desempenho, fermentação ruminal, ionóforo

\begin{abstract}
The effects of replacing monensin with sodium bicarbonate in diets for confined heifers on weight gain $(W G)$, dry matter intake (DMI), feed:gain ratio (FGR) and rumen fermentation parameters were evaluated. Fifity six heifers were utilized (Santa Gertrudis $x$ Braunvieh). Diets were formulated with two levels of concentrate (50\% and $80 \%$ concentrate) with sodium monensin or sodium bicarbonate. The DMI was higest in heifers with an intake of $80 \%$ concentrate. There was not difference when the same concentrate levels were evaluated in relation to the DMI. The heifers at $80 \%$ concentrate showed highest $W G$. There was no significant difference in relation to WG between monensin and bicarbonate treatments and levels concentrate proportions. There were significant effects regarding FGR between treatments. The heifers on $80 \%$ concentrate showed lowest FGR. In the evaluation of $\mathrm{N}-\mathrm{NH}_{3}$, the highest values were observed, on the whole, at 80:20 diets in relation to 50:50 diets. In the additive use, the monensin on 80:20 diets promoted the highest values of $\mathrm{N}-\mathrm{NH}_{3}$ at 1 for 9 hours after feed intake. In the values of ruminal $\mathrm{pH}$, the bicarbonate increased the values on 50:50 at 6 forl 8 hours after feed intake, in relation to the 80:20 diet. In this case, it was concluded that the use of sodium bicarbonate in diets for confined finishing heifers is a viable option for the replacement of monensin sodium.
\end{abstract}

Keywords: beef cattle, performance, buffer, feedlot, ionophore

Recebido em 1 de novembro de 2011

Aceito em 26 de novembro de 2012

E-mail:danielcasagrande@dzo.ufla.br

Apoio financeiro: Bellman Nutrição Animal 


\section{INTRODUÇÃO}

A bovinocultura brasileira tem se destacado mundialmente pelo grande volume de carne exportada, mas, para atingir o mercado externo, foi adaptada à realidade da bovinocultura mundial, mais modernizada, assim tornou-se necessário produzir com alta eficiência. Com o objetivo de atender às exigências do mercado atual, a produção de carne de alta qualidade converge para o sucesso na produção e no abate de bovinos jovens.

O confinamento de bovinos é uma estratégia que requer altos investimentos, principalmente relacionados à alimentação. Nesse sentido, diversas estratégias de manejo e nutricionais têm sido testadas, entre elas o fornecimento de rações com alta proporção de concentrado, para atender ao aumento das exigências nutricionais dos animais de alta produção (Antunes e Rodriguez, 2006).

A principal preocupação nutricional para animais confinados e alimentados com altas quantidades de grãos é em relação ao aumento do risco de desordens fisiológicas, como a acidose ruminal. Embora aumentar a ingestão de carboidratos solúveis seja benéfico, em razão do maior aporte de energia para o ganho de peso, taxas elevadas de ingestão de carboidratos de rápida degradação estão fortemente associadas com acidose ruminal, decréscimo na taxa de crescimento microbiano e distúrbios metabólicos (Nussio et al., 2006).

Com o intuito de buscar o equilíbrio do ecossistema ruminal, várias pesquisas vêm sendo desenvolvidas. O uso de ionóforos e de substâncias alcalinizantes tem sido estudado com vistas a minimizar os efeitos negativos do fornecimento de dietas ricas em concentrado.

Recentemente, a monensina perdeu aceitação social e comercial na União Europeia (UE) devido a possíveis resíduos no produto e à resistência cruzada com bactérias causadoras de patologia humana, sendo o uso proibido na UE em 2006 (Directiva 1831/2003/EEC). É importante ressaltar que, na UE, as autoridades regulatórias têm a permissão de adotar posicionamento preventivo, mesmo sem a existência de fatos científicos que comprovem a prerrogativa. Ao contrário, os EUA se posicionam de acordo com provas de confirmação de fatos, o que permite o uso do aditivo nesse país (Tedeschi et al., 2003).

Assim, especificamente para atender ao nicho de mercado de carne da UE e dos países associados, buscam-se aditivos alternativos aos ionóforos antibióticos. Consequentemente, uma das substâncias alternativas destacada é o bicarbonato de sódio. Objetivou-se com o presente trabalho avaliar efeitos da substituição de monensina sódica por bicarbonato de sódio, em dietas de confinamento com duas relações volumoso:concentrado, sobre o desempenho e os parâmetros ruminais de fêmeas confinadas.

\section{MATERIAL E MÉTODOS}

$\mathrm{O}$ estudo foi realizado no período de agosto a novembro de 2006 , em baias de $15 \mathrm{~m}^{2}$, com piso de cimento semicoberto, e equipadas com comedouros de alvenaria e bebedouros, no município de Jaboticabal, São Paulo. Foram utilizadas 56 novilhas Santa Gertrudes x Braunvieh no experimento para avaliação do desempenho, do consumo, da conversão alimentar, do rendimento de carcaça e da eficiência alimentar e quatro animais no experimento para avaliação dos parâmetros ruminais, com média de $250 \mathrm{~kg}$ de peso corporal em jejum e idade de 16 meses, adquiridos da mesma propriedade (Fazendas Bartira, Grupo Brascan). Antes do início do experimento, os animais foram identificados e receberam os tratamentos sanitários, como banho carrapaticida, everminação e vacinação preventiva contra febre aftosa e clostridioses.

Os tratamentos foram em arranjo fatorial $2 \times 2$, duas relações de volumoso e concentrado, uma com $50 \%$ de concentrado e outra com $80 \%$ de concentrado com base na matéria seca, aliados ao uso de dois aditivos: monensina sódica ou bicarbonato de sódio. O consumo estipulado de monensina sódica e bicarbonato de sódio por animal/dia foi de $150 \mathrm{mg}$ e $150 \mathrm{~g}$, respectivamente. $\mathrm{O}$ volumoso utilizado para compor as quatro dietas testadas no experimento foi composto de silagem de milho e cana-deaçúcar picada numa proporção de 60:40, respectivamente.

As dietas foram formuladas para serem isoproteicas, com aproximadamente $13 \%$ de 
proteína bruta (Tab. 1), e foram balanceadas de acordo com o proposto pelo Cornell Net Carbohidrate and Protein System (CNCPS).

Os animais foram alimentados à vontade, com oferta de alimento $10 \%$ superior ao consumo voluntário, em refeição diária às oito horas. A colheita da cana-de-açúcar foi feita de forma mecanizada, sendo realizada diariamente, antes do fornecimento aos animais. A silagem foi retirada do silo pouco antes do horário de alimentação e misturada à cana-de-açúcar e ao concentrado no momento do fornecimento aos animais. A cada dois dias, antes do fornecimento da dieta, foram colhidas e pesadas as sobras. Subamostras foram obtidas para determinação do conteúdo de matéria seca, de acordo com AOAC
(Association..., 1990), para ajuste da oferta de alimento e posterior cálculo do consumo e da conversão alimentar. As sobras foram amostradas, no momento de sua retirada, para análise laboratorial. Essas amostras, bem como as amostras de silagem e cana-de- açúcar, foram pré-secas em estufa de ar forçado a $55^{\circ} \mathrm{C}$ por 72 horas para determinação do teor de matéria seca, sendo sequencialmente moídas em moinho tipo Willey com peneira de malha de $1 \mathrm{~mm}$. Posteriormente, foram determinados os teores de matéria seca total (MS) e proteína bruta (PB) de acordo com AOAC (Association..., 1990), extrato etéreo (EE), fibra em detergente neutro (FDN), segundo Van Soest et al. (1991), e NDT estimado conforme NRC (National..., 1996).

Tabela 1. Composição bromatológica dos volumosos e formulação inicial (\% MS) das dietas experimentais

\begin{tabular}{lcccc}
\hline \multirow{2}{*}{ Volumoso } & \multicolumn{3}{c}{ Composição bromatológica (\%MS) } \\
\cline { 2 - 5 } Silagem de milho & MS & PB & FDN & FDA \\
Cana-de-açúcar & 31,42 & 7,94 & 48,60 & 21,74 \\
Ingrediente & 29,86 & 2,54 & 55,74 & 25,13 \\
\hline Silagem de milho & \multicolumn{4}{c}{ Dieta } \\
Cana-de-açúcar & $50 \% \mathrm{M}$ & $50 \% \mathrm{BS}$ & $80 \% \mathrm{M}$ & $80 \% \mathrm{BS}$ \\
Polpa cítrica & 30 & 30 & 12 & 12 \\
Farelo de algodão & 20 & 20 & 8 & 8 \\
Núcleo mineral com ureia e monensina & 35 & 35 & 65 & 65 \\
Núcleo mineral com ureia e bicarbonato de sódio & 12 & 12 & 12 & 12 \\
\hline \multirow{2}{*}{ Composição bromatológica da dieta (\%MS) } & 3 & 0 & 3 & 0 \\
& 0 & 3 & 0 & 3 \\
\hline MS (\%) & \multicolumn{4}{c}{ Dieta } \\
PB ${ }^{2}(\% \mathrm{MS})$ & $50 \% \mathrm{M}$ & $50 \% \mathrm{BS}$ & $80 \% \mathrm{M}$ & $80 \% \mathrm{BS}$ \\
FDN $\% \mathrm{MS})$ & 45,51 & 45,51 & 65,12 & 65,12 \\
EE (\%MS) & 13,03 & 13,03 & 13,15 & 13,15 \\
NDT (\%MS) & 37,53 & 37,53 & 30,25 & 30,25 \\
\hline
\end{tabular}

$50 \% \mathrm{M}-50 \%$ de concentrado com monensina sódica; 50\%BS - 50\% de concentrado com bicarbonato de sódio; $80 \% \mathrm{M}-80 \%$ de concentrado com monensina sódica; $80 \% \mathrm{BS}-80 \%$ de concentrado com bicarbonato de sódio.

$\mathrm{Na}$ avaliação dos parâmetros ruminais, foram utilizados quatro animais fistulados no rúmen. $\mathrm{O}$ período de adaptação dos animais à dieta foi de 15 dias, e posteriormente se realizou a amostragem do conteúdo ruminal nos tempos zero, uma, três, seis, nove, 12, 18 e 24 horas, sendo que o tempo zero correspondeu à amostragem antes do fornecimento da dieta, que ocorreu às sete horas da manhã. Os demais tempos de amostragem correspondem às horas após a refeição. Amostraram-se aproximadamente $100 \mathrm{~g}$ de conteúdo do rúmen, que foram depositados sobre pano de algodão e espremidos sobre tamis com abertura de malha de $0,05 \mathrm{~mm}$.

A determinação de $\mathrm{pH}$ das amostras de líquido ruminal foi feita com auxílio de peagâmetro calibrado com tampão pH 4 e 7, e a concentração do nitrogênio amoniacal $\left(\mathrm{N}-\mathrm{NH}_{3}\right)$ por meio da destilação da amostra na presença de óxido de 
magnésio (Bremner e Keeney, 1965), sendo realizada imediatamente após a coleta.

O experimento para avaliação dos parâmetros ruminais foi conduzido em delineamento de quadrado latino (na coluna o animal e na linha o período), em esquema de análise de parcelas subdivididas (na subparcela as horas de amostragem do líquido ruminal). As confrontações das interações foram aferidas pelo teste $\mathrm{t}$, ao nível de $95 \%$ de confiança. Os dados foram processados e analisados pelo programa SAS (Statistical..., 2002).

O período total de confinamento dos animais para avaliação do desempenho, do consumo, da conversão alimentar, da eficiência alimentar e do rendimento de carcaça foi de 112 dias, e os primeiros 28 dias caracterizaram a adaptação dos animais ao ambiente do confinamento e à dieta alimentar. Os 56 animais foram distribuídos em quatro tratamentos, duas porcentagens de concentrado $\mathrm{x}$ dois tipos de aditivos - divididos aleatoriamente em 28 baias, sendo dois animais por baia, pareados por peso corporal.

Os animais foram pesados no início e no final do período experimental e a cada 28 dias, após jejum completo de 15 horas. A fase de coleta de dados foi dividida em três períodos. O consumo voluntário dos alimentos foi registrado por meio das pesagens da quantidade oferecida e da sobra. A conversão alimentar - $\mathrm{kg}$ de alimento consumido $/ \mathrm{kg}$ de ganho de peso - e a eficiência alimentar - $\mathrm{kg}$ de ganho de peso/kg de alimento consumido - foram calculadas a partir dos dados de consumo e do ganho de peso.

O delineamento experimental utilizado para análise das variáveis de desempenho foi inteiramente ao acaso, com quatro tratamentos e 14 repetições. Foi realizada análise de variância aplicando-se o teste Tuckey para comparação de médias a $5 \%$ de significância. $\mathrm{O}$ peso corporal inicial foi usado como covariável na análise estatística. Os dados foram processados e analisados no programa SAS (Statistical..., 2002).

\section{RESULTADOS E DISCUSSÃO}

Em relação ao padrão de fermentação ruminal (Tab. 2), valores superiores de $\mathrm{N}_{-} \mathrm{NH}_{3}$ no rúmen foram observados nas dietas com $80 \%$ de concentrado. Nesse tratamento, a utilização de monensina proporcionou valores superiores comparados ao uso de bicarbonato de sódio, no entanto essas diferenças foram significativas somente nos tempos uma e nove horas após o fornecimento da dieta. Esses dados não estão de acordo com observações feitas por Morais et al. (2006). Os autores relatam que a utilização de ionóforos melhora o metabolismo de $\mathrm{N}$ pelas bactérias ruminais, diminuindo a absorção de amônia e aumentando a quantidade de proteínas de origem alimentar que chega ao intestino delgado.

Nas dietas com $50 \%$ de concentrado, a inclusão de monensina ou bicarbonato não alterou os teores de $\mathrm{N}-\mathrm{NH}_{3}$ no rúmen. Nesse caso, valores superiores de $\mathrm{N}-\mathrm{NH}_{3}$ foram observados com uma hora após o fornecimento da dieta. Nos tratamentos com $80 \%$ de concentrado, foi observado um prolongamento no tempo em que as concentrações de $\mathrm{N}-\mathrm{NH}_{3}$ foram elevadas, com uma hora após o fornecimento da dieta, estendendo-se até três horas.

Tabela 2. Teores de nitrogênio amoniacal no líquido ruminal (mg/dL) de novilhas jovens, fistuladas, mantidas em confinamento e que receberam dietas com diferentes porcentagens de concentrado com monensina sódica ou bicarbonato de sódio

\begin{tabular}{ccccccccc}
\hline \multirow{2}{*}{ Dieta } & \multicolumn{7}{c}{ Horas após o fornecimento da dieta } \\
\cline { 2 - 8 } & 0 & 1 & 3 & 6 & 9 & 12 & 18 & 24 \\
\hline $50 \% \mathrm{BS}$ & $10,4 \mathrm{Bbc}$ & $21,3 \mathrm{Ca}$ & $13,8 \mathrm{Bb}$ & $7,8 \mathrm{Bbc}$ & $4,9 \mathrm{Cc}$ & $4,5 \mathrm{Bc}$ & $5,5 \mathrm{Bc}$ & $6,4 \mathrm{Cc}$ \\
$50 \% \mathrm{MS}$ & $9,0 \mathrm{Bb}$ & $20,1 \mathrm{Ca}$ & $10,8 \mathrm{Bb}$ & $7,9 \mathrm{Bb}$ & $6,6 \mathrm{Cb}$ & $5,7 \mathrm{Bb}$ & $6,4 \mathrm{Bb}$ & $7,3 \mathrm{BC} \mathrm{b}$ \\
$80 \% \mathrm{BS}$ & $19,5 \mathrm{Abc}$ & $37,4 \mathrm{Ba}$ & $32,2 \mathrm{Aa}$ & $22,9 \mathrm{Ab}$ & $15,0 \mathrm{Bcd}$ & $12,4 \mathrm{Ad}$ & $12,3 \mathrm{Ad}$ & $13,6 \mathrm{ABcd}$ \\
$80 \% \mathrm{MS}$ & $18,5 \mathrm{Acd}$ & $47,8 \mathrm{Aa}$ & $30,2 \mathrm{Ab}$ & $24,5 \mathrm{Abc}$ & $23,3 \mathrm{Ac}$ & $14,0 \mathrm{Ad}$ & $13,1 \mathrm{Ad}$ & $16,2 \mathrm{Ad}$ \\
\hline
\end{tabular}

Médias seguidas por letras distintas, maiúsculas na coluna e minúsculas na linha, diferem entre si pelo teste $\mathrm{t}$ $(\mathrm{P}<0,05)$.

$50 \% \mathrm{MS}-50 \%$ de concentrado com monensina sódica; $50 \% \mathrm{BS}$ - 50\% de concentrado com bicarbonato de sódio; $80 \%$ MS $-80 \%$ de concentrado com monensina sódica; $80 \%$ BS $-80 \%$ de concentrado com bicarbonato de sódio. 
Nas dietas com $50 \%$ de concentrado, a utilização de bicarbonato de sódio promoveu valores de $\mathrm{pH}$ superiores, com exceção dos tempos uma e 24 horas (Tab. 3). Os valores de $\mathrm{pH}$ decresceram com uma hora após o fornecimento da dieta e tenderam a se elevar com 12 horas. No tratamento com $80 \%$ de concentrado, a diferença nos valores de $\mathrm{pH}$ foi observada somente no tempo 18 horas; nos demais, a inclusão de monensina sódica ou de bicarbonato de sódio não interferiu no $\mathrm{pH}$ do rúmen.

Tabela 3. Valores de $\mathrm{pH}$ no líquido ruminal $(\mathrm{mg} / \mathrm{dL})$ de novilhas jovens, fistuladas, mantidas em confinamento e que receberam dietas com diferentes porcentagens de concentrado com monensina sódica ou bicarbonato de sódio

\begin{tabular}{ccccccccc}
\hline \multirow{2}{*}{ Dieta } & \multicolumn{7}{c}{ Horas após o fornecimento da dieta } \\
\cline { 2 - 9 } & 0 & 1 & 3 & 6 & 9 & 12 & 18 & 24 \\
\hline $50 \% \mathrm{BS}$ & $7,3 \mathrm{Aa}$ & $6,4 \mathrm{Acd}$ & $6,3 \mathrm{Acd}$ & $6,2 \mathrm{Ad}$ & $6,2 \mathrm{Ad}$ & $6,4 \mathrm{Ac}$ & $6,8 \mathrm{Ab}$ & $6,9 \mathrm{Ab}$ \\
$50 \% \mathrm{MS}$ & $6,8 \mathrm{Ba}$ & $6,2 \mathrm{Ac}$ & $6,0 \mathrm{Bcd}$ & $5,9 \mathrm{Bd}$ & $5,8 \mathrm{Bd}$ & $6,1 \mathrm{Bcd}$ & $6,6 \mathrm{Bb}$ & $6,8 \mathrm{ABa}$ \\
$80 \% \mathrm{BS}$ & $7,1 \mathrm{Aba}$ & $6,4 \mathrm{Abc}$ & $6,2 \mathrm{ABc}$ & $5,9 \mathrm{Bd}$ & $5,6 \mathrm{Be}$ & $5,9 \mathrm{Bd}$ & $6,2 \mathrm{Cc}$ & $6,6 \mathrm{Bb}$ \\
$80 \% \mathrm{MS}$ & $7,0 \mathrm{Aba}$ & $6,3 \mathrm{Ab}$ & $6,0 \mathrm{Bcd}$ & $5,9 \mathrm{Bd}$ & $5,6 \mathrm{Be}$ & $5,9 \mathrm{Bd}$ & $6,5 \mathrm{Bb}$ & $6,8 \mathrm{ABa}$ \\
\hline
\end{tabular}

Médias seguidas por letras distintas, maiúsculas na coluna e minúsculas na linha, diferem entre si pelo teste $\mathrm{t}$ $(\mathrm{P}<0,05)$.

$50 \% \mathrm{MS}-50 \%$ de concentrado com monensina sódica; $50 \% \mathrm{BS}-50 \%$ de concentrado com bicarbonato de sódio; 80\% MS - 80\% de concentrado com monensina sódica; $80 \%$ BS - 80\% de concentrado com bicarbonato de sódio.

Em nenhum dos tratamentos avaliados foi observado quadro clínico de acidose ruminal. A acidose ruminal subaguda é caracterizada por quedas repetidas no $\mathrm{pH}$ ruminal entre 5,2 e 5,6, geralmente resultando da ingestão de grande quantidade de carboidratos altamente fermentáveis, o que leva a um aumento dos ácidos orgânicos no rúmen. Segundo Duffield et al. (2004), os valores de $\mathrm{pH}$ entre 5,6 e 5,8 são considerados marginais. O período de duração por dia em que o $\mathrm{pH}$ ruminal encontra-se inferior a 5,6 ou 5,8 é mais importante para determinar acidose ruminal que a média diária do $\mathrm{pH}$ ruminal (Gozho et al., 2005; Rustomo et al., 2006). O pH ruminal esteve abaixo de 5,8 somente na amostragem de nove horas após o fornecimento da dieta. Vale ressaltar que, ao amanhecer, na coleta de 24 horas após o fornecimento da dieta, o rúmen dos animais apresentava sinais claros de timpanismo espumoso.

Não houve efeito significativo $(\mathrm{P}>0,05)$ da interação porcentagem de concentrado na dieta $\mathrm{x}$ aditivo sob nenhuma das variáveis de desempenho estudadas. Houve maior $(\mathrm{P}<0,05)$ consumo pelos animais que receberam $80 \%$ de concentrado, durante o período experimental, em relação aos que consumiram dieta com $50 \%$ de concentrado (Tab. 4).Não foi observado efeito $(\mathrm{P}>0,05)$ dos aditivos avaliados sobre o consumo e matéria seca e nem sobre o desempenho do animais.

Tabela 4. Desempenho, conversão alimentar e rendimento de carcaça de novilhas em confinamento e que receberam dietas com diferentes porcentagens de concentrado com monensina sódica ou bicarbonato de sódio

\begin{tabular}{|c|c|c|c|c|c|}
\hline \multirow[t]{2}{*}{ Variável } & \multicolumn{2}{|c|}{$\begin{array}{c}\% \text { de concentrado na } \\
\text { dieta }\end{array}$} & \multicolumn{2}{|c|}{ Aditivo } & \multirow[t]{2}{*}{$\mathrm{CV} \%$} \\
\hline & 50 & 80 & Bicarbonato & Monensina & \\
\hline Consumo MS, kg/dia & $6,97 b$ & $8,38 \mathrm{a}$ & $7,82 \mathrm{~A}$ & $7,53 \mathrm{~A}$ & 13,0 \\
\hline Consumo MS, \% PV & $2,26 b$ & $2,59 \mathrm{a}$ & $2,47 \mathrm{~A}$ & $2,38 \mathrm{~A}$ & 12,3 \\
\hline Consumo PB, kg/dia & $1,82 b$ & $2,20 \mathrm{a}$ & $2,05 \mathrm{~A}$ & $1,97 \mathrm{~A}$ & 13,0 \\
\hline Ganho de peso, $\mathrm{kg} / \mathrm{dia}$ & $1,05 b$ & $1,36 \mathrm{a}$ & $1,18 \mathrm{~A}$ & $1,23 \mathrm{~A}$ & 14,9 \\
\hline Conversão alimentar, $\mathrm{kg} / \mathrm{kg}$ & $6,96 a$ & $6,21 b$ & $6,75 \mathrm{~A}$ & $6,42 \mathrm{~A}$ & 12,9 \\
\hline Eficiência alimentar, $\mathrm{kg} / \mathrm{kg}$ & $0,15 b$ & $0,16 \mathrm{a}$ & $0,15 \mathrm{~A}$ & $0,16 \mathrm{~A}$ & 12,9 \\
\hline Peso corporal final, $\mathrm{kg}$ & $354 b$ & $380 \mathrm{a}$ & $365 \mathrm{~A}$ & $369 \mathrm{~A}$ & 4,1 \\
\hline Rendimento de carcaça, \% & $50,03 \mathrm{~b}$ & $51,51 \mathrm{a}$ & $50,72 \mathrm{~A}$ & $50,82 \mathrm{~A}$ & 1,8 \\
\hline
\end{tabular}

Médias seguidas de letras distintas minúsculas, para avaliar o efeito da relação volumoso:concentrado, e maiúsculas, para avaliar o efeito do tamponante, diferem entre sim pelo teste Tukey $(\mathrm{P}<0,05)$. 
A maior porcentagem de volumoso na composição da dieta causou redução no consumo de matéria seca, independentemente do aditivo utilizado (Tab. 4). Mertens (1994) e Coelho da Silva (2006) atribuíram o controle da ingestão de alimentos a três mecanismos básicos: o fisiológico, que é regulado pelo balanço nutricional da dieta, especificamente relacionado à manutenção do equilíbrio energético; o físico, que está associado à capacidade de distensão do rúmen-retículo em função do teor de fibra em detergente neutro (FDN) da ração; e a regulação psicogênica, relacionada à resposta do animal a fatores inibidores ou estimuladores no alimento ou no manejo alimentar. Como o volumoso utilizado no presente estudo era constituído de silagem de milho e cana-de-açúcar, podem-se atribuir os menores valores de consumo de matéria seca dos animais submetidos à dieta contendo $50 \%$ de volumoso ao enchimento do trato gastrointestinal.

Nagaraja et al. (1997) relataram que a atuação dos ionóforos sobre o consumo de alimentos e/ou sobre a eficiência de ganho de peso é muito dependente dos componentes da dieta alimentar e da relação volumoso:concentrado, mas que, de maneira geral, a eficiência alimentar é melhorada. Valadares Filho e Pina (2006) ressaltaram que a atuação da monensina sobre o processo de fermentação ruminal causa redução no consumo de matéria seca, sem alterar o ganho de peso, e, consequentemente, melhora a conversão alimentar em animais confinados. Vargas et al. (2001) observaram maior redução no consumo de alimento relacionado à suplementação com monensina à medida que o nível de concentrado na dieta aumentou. Os autores sugerem que, no caso de animais em confinamento, em que o nível de energia - efeito fisiológico - regula o consumo, o aumento da eficiência energética favorece a redução do consumo de alimentos por satisfazer as necessidades nutricionais.

O uso de ionóforos na dieta de bovinos reflete resultados bastante promissores, principalmente na atuação em dietas de bovinos confinados, resultando em melhor eficiência de produção e reduzida emissão de metano no ambiente. No entanto, no presente estudo, não foi observada diferença estatística no consumo entre os animais que receberam os diferentes aditivos.
A ingestão de proteína seguiu o mesmo comportamento do consumo de matéria seca, ou seja, foi maior nos animais que consumiram dieta com $80 \%$ de concentrado em relação aos da dieta com $50 \%$ de concentrado $(\mathrm{P}<0,05)$, no entanto não diferiu em função do tipo de aditivo utilizado $(\mathrm{P}>0,05)$. O maior consumo de matéria seca foi o principal fator para alteração sobre a ingestão de proteína, uma vez que as dietas formuladas foram isoproteicas.

Os maiores ganhos de peso foram observados nos animais que receberam dieta com maiores quantidades de concentrado $(\mathrm{P}<0,05)$ e, consequentemente, apresentaram maior peso ao final do experimento (Tab. 4).

Henrique et al. (1998) obtiveram ganho de peso médio semelhante ao observado no presente estudo $(1,27 \mathrm{~kg} / \mathrm{dia})$, ao avaliarem novilhas Santa Gertrudes (18 meses de idade e $313 \mathrm{~kg}$ ), com dieta composta de $80 \%$ de concentrado e $20 \%$ de silagem de milho, com níveis proteico e energético semelhantes. Os resultados de ganho de peso diário obtidos no presente estudo foram semelhantes aos observados por Fernandes et al. (2007), que obtiveram ganhos médios de $1,32 \mathrm{~kg} /$ dia de ganho de peso diário de novilhas Canchim terminadas em confinamento e alimentadas com dietas com relação volumoso:concentrado de 40:60. Em relação ao ganho de peso entre os tratamentos com monensina sódica e com bicarbonato de sódio nas duas relações volumoso:concentrado, não houve diferença estatística $(\mathrm{P}>0,05)$.

Um dos fatores mais importantes na determinação do peso de abate é a eficiência de ganho de peso nas várias fases da curva de crescimento. Quanto maior a taxa de ganho, maior a eficiência de conversão em função da diluição das exigências de manutenção, que são relativamente constantes (Lanna e Packer, 1998).

Quanto à conversão alimentar dos animais entre os tratamentos avaliados, o tratamento com $80 \%$ de concentrado propiciou menor conversão alimentar $(6,21 \mathrm{~kg}$ de MS ingerida/ $\mathrm{kg}$ de ganho) $(\mathrm{P}<0,05)$, necessitando, assim, de menor quantidade de matéria seca para ganhar $1 \mathrm{~kg}$ de peso corporal. Resultado semelhante foi observado por Henrique et al. (1998), que apresentaram conversão alimentar média de $6,75 \mathrm{~kg}$ em novilhas Santa Gertrudes, alimentadas 
com dieta com $80 \%$ de concentrado. Manzano et al. (1999) obtiveram, com novilhas Canchim, conversão alimentar de aproximadamente $8 \mathrm{~kg}$, pior que a obtida neste trabalho $(7,51 \mathrm{~kg})$ com novilhas Santa Gertrudes alimentadas com rações com $55 \%$ de concentrado.

Segundo Goodrich et al. (1984), a inclusão do ionóforo na dieta de bovinos em confinamento, com alta proporção de grãos na dieta, na maioria dos casos, proporciona redução no consumo de matéria seca e respostas positivas no ganho de peso. Outros autores (Zinn e Borques, 1993; Salles e Lucci, 2000) não observaram efeito significativo da monensina sobre a conversão alimentar. Os efeitos da monensina sódica só podem ser observados quando o nitrogênio suplementado está na forma de proteína verdadeira, peptídeos ou aminoácidos. Dessa forma, as dietas com baixo teor de proteína livre ou com elevado teor de nitrogênio não proteico parecem sofrer um efeito menor da monensina sódica do que as dietas com elevado teor de proteína e carência de energia. Os efeitos da monensina sódica são tanto maiores quanto maior o teor de proteína bruta da dieta (Lana et al., 1997). Como as dietas deste experimento apresentavam porcentagens de proteína relativamente baixas e uma parte considerável oriunda de nitrogênio não proteico, não foi observado efeito da monensina sódica sobre o consumo dos animais.

Houve diferença nos valores de eficiência alimentar entre as porcentagens de concentrado na dieta. A melhora na eficiência alimentar dos animais submetidos ao tratamento com $80 \%$ de concentrado deveu-se ao aumento no ganho de peso dos animais, o que sugere maior aporte de energia em dietas com maior nível de concentrado em decorrência do maior aporte de carboidratos solúveis. Não foi observada diferença estatística $(\mathrm{P}>0,05)$ entre os tamponantes utilizados. Leme et al. (2003) avaliaram dietas com altas porcentagens de concentrado e não encontraram diferenças no ganho de peso e na eficiência alimentar ao fornecerem bagaço in natura como volumoso exclusivo nas proporções de 15,21 ou $27 \%$ da MS da dieta.

A porcentagem de concentrado na dieta alterou significativamente $o$ rendimento de carcaça dos animais $(\mathrm{P}<0,05)$. Os animais submetidos aos tratamentos com $80 \%$ de concentrado apresentaram maior rendimento de carcaça (Tab. 4). O rendimento de carcaça é calculado em função do peso de carcaça quente e do peso corporal do animal. Nesse contexto, as variações observadas no rendimento de carcaça podem ser atribuídas a vários fatores, entre eles pode-se destacar a maior taxa de passagem de uma dieta. Segundo Antunes e Rodrigues (2006), dietas ricas em carboidratos não fibrosos apresentam maior taxa de passagem que dietas ricas em carboidratos fibrosos. Portanto, os animais que consumiam a dieta com $80 \%$ de concentrado apresentavam o trato gastrointestinal (TGI) mais vazio na hora das pesagens, visto que todos os animais foram deixados em jejum por 15 horas antes das pesagens e, por conseguinte, tornaramse mais leves.

Outro fator que pode causar variação no rendimento de carcaça é o tamanho do trato gastrointestinal (TGI) dos animais. Ferreira et al. (2000) mostraram que houve redução no tamanho do TGI com o aumento da inclusão de concentrado na dieta. Possivelmente os animais submetidos às dietas com $80 \%$ de concentrado apresentavam menor conteúdo de TGI. Outro fator que ajuda a explicar o maior rendimento de carcaça dos animais submetidos às dietas com $80 \%$ de concentrado foi maior ganho de peso e, consequentemente, maior deposição de músculo e gordura, o que contribuiu para o maior rendimento de carcaça.

\section{CONCLUSÃO}

Os animais que consomem dietas com elevada proporção de concentrado apresentam maior ganho de peso do que animais com menor porcentagem de concentrado na dieta. A melhora na conversão alimentar, no ganho de peso, na eficiência alimentar e no rendimento de carcaça nas dietas com $80 \%$ de concentrado pode viabilizar o uso de confinamento com alto grão, visto que reduz o tempo de confinamento e gastos com alimentação. $\mathrm{O}$ uso de bicarbonato de sódio em dietas para animais em confinamento mostrou-se uma opção viável em relação à substituição da monensina sódica na manipulação da fermentação ruminal. A utilização de novilhas destinadas à produção de carne mostrou-se uma opção viável, visto que elas apresentaram um desempenho satisfatório. 


\section{AGRADECIMENTO}

À Bellman Nutrição Animal Ltda. e a à Fazenda Bartira/Grupo Brascan, pelas contribuições necessárias para a realização do experimento.

\section{REFERÊNCIA}

ANTUNES, R.C.; RODRIGUEZ, N.M. Metabolismo dos carboidratos não estruturais. In: BERCHIELLI, T.T.; PIRES, A.V.; OLIVEIRA, S.G. (Eds). Nutrição de ruminantes. 1.ed. Jaboticabal: Funep, 2006. 583p.

ASSOCIATION of official analytical chemists AOAC. Official methods of analysis. 15, Virginia, 1990. Arlington: v.1. 1298 p. 1990.

BREMNER, J.M.; KEENEY, D.R. Steam distillation methods for determination of ammonium, nitrate and nitrite. Anal. Chim. Acta, v.32, p.485-495, 1965.

COELHO DA SILVA, J.F. Mecanismos reguladores de consumo. In: BERCHIELLI, T.T.; PIRES, A.V.; OLIVEIRA, S.G. (Eds). Nutrição de ruminantes. 1.ed. Jaboticabal: Funep, 2006. 583p.

DUFFIELD, T.; PLAIZIER, J.C.; FAIRFIELD, A. et al. Comparison of techniques for measurement of rumen $\mathrm{pH}$ in lactating dairy cows. J. Dairy Sci., v.87, p.59-66, 2004.

FERNANDES, A.R.M.F.; SAMPAIO, A.A.M.; HENRIQUE, W. et al. Avaliação econômica e desempenho de machos e fêmeas Canchim em confinamento alimentados com dietas à base de silagem de milho e concentrado ou cana-deaçúcar e concentrado contendo grãos de girassol. Rev. Bras. Zootec., v.36, p.855-864, 2007.

FERREIRA, M.A.; VALADARES FILHO, S.C.; MUNIZ, E.B. et al. Características das Carcaças, Biometria do Trato Gastrintestinal, Tamanho dos Órgãos Internos e Conteúdo Gastrintestinal de Bovinos F1 Simental x Nelore Alimentados com Dietas contendo Vários Níveis de Concentrado. Rev. Bras. Zootec., v.29, p.1174-1182, 2000.

GOODRICH, R.D.; GARRET, J.E.; GAST, D.R. et al. Influence of monensin on the performance of cattle. J. Anim. Sci., v.58, p.1484-1498, 1984.
GOZHO, G.N.; PLAIZIER, J.C.; KRAUSE, D.O. et al. Subacute ruminal acidosis induces ruminal lipopolysaccharide endotoxin release and triggers an inflammatory response. J. Dairy Sci., v.88, p.1399-1403, 2005.

HENRIQUE, W.; LEME, P.R.; LANNA, D.P.D. et al. Substituição de Amido por Pectina em Dietas com Diferentes Níveis de Concentrado. 1. Desempenho Animal e Características da Carcaça. Rev. Bras. Zootec., v.27, p.1206-1211, 1998.

LANA, P.R.; FOX, D.G.; RUSSELL, J.B. et al. Influence of monensin on Holstein steers fed high-concentrate diets containing soybean meal or urea. J. Anim. Sci., v.75, p.2571, 1997.

LANNA, D.P.; PACKER, I.V. Eficiência biológica e econômica de bovinos de corte. In: WORKSHOP SOBRE QUALIDADE DA CARNE E MELHORAMENTO GENÉTICO DE BOVINOS, 1., 1998, São Carlos. Anais... São Carlos: EMBRAPA/FUNDEPEC. 1998. p.83104.

LEME, P.R.; SILVA, S.L.; PEREIRA, A.S.C. et al. Utilização do bagaço de cana-de-açúcar em dietas com elevada proporção de concentrados para novilhos Nelore em confinamento. Rev. Bras. Zootec., v.32, p.1786-1791, 2003.

MANZANO, A.; ESTEVES, S.N.; FREITAS, A.R. et al. Eficiência de utilização de nutrientes em novilhas das raças Canchim e Nelore e cruzadas Canchim - Nelore. Rev. Bras. Zootec., v.28, p.1375-1381, 1999.

MERTENS, D.R. Regulation of forage intake. In: FAHEY JUNIOR, G.C.; MOSER, L.E.; MERTENS, D.R. (Eds.). Forage quality, evaluation and utilization. American Society of Agronomy, Crop Science of America, Soil Science of America, Madison, WI. p.450-493. 1994.

MORAIS, J.A.S; BERCHIELLI, T.T; REIS, R.A. Aditivos. In: BERCHIELLI, T.T.; PIRES, A.V; OLIVEIRA, S.G. Nutrição de ruminantes. Jaboticabal:Funep, 2006. 583p.

NAGARAJA, T.G. NEWBOLD, C.J.; VAN NEVEL, C.J. DEMEYER, D.I. Manipulation of ruminal fermentation, In: HOBSON , P.N.; STEWART, C.S. (Eds). The rumen microbian ecosystem. London: Blackie Academy \& professional, 1997. p.523. 
NATIONAL research council - NRC. Nutrient requirements of beef cattle. 7.ed. Washington, D.C.: National Academy Press, 1996. 381p.

NUSSIO, L.G.; CAMPOS, F.P.; LIMA, M.L.M. Metabolismo de carboidratos estruturais. In: BERCHIELLI, T.T.; PIRES, A.V.; OLIVEIRA, S.G. (Eds). Nutrição de ruminantes. 1.ed. Jaboticabal: Funep, 2006. 583p.

RUSTOMO, B.; ALZAHAL, O.; ODONGO, N.E. et al. Effects of rumen acid load from feed and forage particle size on ruminal $\mathrm{pH}$ and dry matter intake in the lactating dairy cow. J. Dairy Sci., v.89, p.4758-4768. 2006.

SALLES, M.S.V.; LUCCI, C.S. Monensina para bezerros em crescimento acelerado. 1. Desempenho. Rev. Bras. Zootec., v.29, p.573$581,2000$.

STATISTICAL Analyses System Institute SAS. "SAS User's Guide: Statistic". SAS Institute INC., Cary, NC, 2002.

TEDESCHI, L.O.; FOX, D.G.; TYLUTKI, T.P. Potential environmental benefits of ionophores in ruminant diets. J. Environmental Quality, v.32, p.1591, 2003.
VALADARES FILHO, S.C.; PINA, D.S. Fermentação ruminal. In: BERCHIELLI, T.T.; PIRES, A.V.; OLIVEIRA, S.G. (Eds). Nutrição de ruminantes. 1.ed. Jaboticabal: Funep, 2006. $583 \mathrm{p}$.

VAN SOEST, P.J.; ROBERTSON, J.B.; LEWIS, B.A. Symposium: carboydrate metodology, metabolism, and nutritional implications in dairy cattle. J. Dairy Sci., v.74, p.3583-3597, 1991.

VARGAS, L.H.; LANA, R.P.; MÂNCIO, A.B. et al. Influência de Rumensin®, óleo de soja e níveis de concentrado sobre o consumo e os parâmetros fermentativos ruminais em bovinos. Rev. Bras. Zootec., v.30, p.1650-1658, 2001.

ZINN, R.A.; BORQUES, J.L. Influence of sodium bicarbonate and monensin in utilization of a fat-supllemented, high-energy growingfinishing diet by feedlot steers. J. Anim. Sci., v.71, p.18-25, 1993. 